\title{
Editorial
}

\section{Acceso a la salud un derecho universal independiente del origen o el destino: Qué debe tener presente el ginecólogo obstetra cuando atiende a una mujer migrante.}

Recientemente, la Federación Internacional de Ginecólogos y Obstetras en su sitio web ha hecho un llamado de atención sobre la emergencia humanitaria y sanitaria que se ha producido con la diáspora de refugiados Sirios, un fenómeno considerado como el más grave desde lo acaecido en tiempos de la segunda guerra mundial. En efecto, desde el inicio del conflicto, aproximadamente 1,5 millones de refugiados sirios han escapado al Líbano creando más de 2000 asentamientos y espacios improvisados alrededor de todo el país. Como es de esperar para tal escenario terrible, los refugiados son mayoritariamente mujeres y niños desvalidos en necesidad de medios de subsistencia, cuidados de salud, educación y protección. Tales demandas han puesto en jaqueca no sólo al gobierno libanés, a los organismos y agencias internacionales, a las autoridades sanitarias sino también a los médicos que ejercen, incluyendo ginecólogos y obstetras, y habitan en las regiones donde los refugiados han logrado llegar en su escapada.

Tal cómo lo deja entrever el comunicado de FIGO, los ginecólogos obstetras han debido aprender el idioma, conocer de la cultura y costumbres sirias, de la problemática que los aqueja y de las necesidades sanitarias que presentan. Entre ellas, el proveer de cuidado antenatal, el atender partos en campamentos y hospitales de campaña, con elementos mínimos y tratando de mantener bajo control la mortalidad materna y perinatal, habitual elevada en situaciones de extrema pobreza o de guerra. Junto a ello lidiar con el comercio y explotación sexual por subsistencia, matrimonios adolescentes por conveniencia y tratar traumas psicológicos producto de violaciones, violencia, asaltos y muerte. Por último, hacer extensivas coberturas para programas de planificación familiar, tamizaje de patología cervical preinvasora, vacunas, suplementación alimenticia, entre otras.

Probablemente, los refugiados sirios arribando a Chile sean pocos y no representen el drama ni demanda de recursos económicos que generan en los países limítrofes o cercanos. Independiente de su número ameritan toda nuestra empatía, dedicación, esfuerzo y profesionalismo médico, una característica que históricamente ha prestigiado al profesional médico chileno, en particular a los ginecólogos obstetras. No hay espacio para la discriminación o prejuicio injustificados sino para el involucramiento y aprendizaje sobre necesidades y enfermedades particulares que puedan ser más prevalentes en dicha población.

Tan trágica situación no puede más que permitir reconocer y recordar la importancia del buen trato, del aprender e involucrarse como especialistas en las demandas sanitarias que conllevan todos los migrantes que hoy llegan por razones diversas al país ya sea para radicarse o en transición hacia mejores destinos. Como especialistas debemos conocer de la cultura del pueblo haitiano, venezolano, dominicano, peruano, de las enfermedades prevalentes en dichas latitudes (algunas inexistentes en nuestro país u otras ya erradicadas gracias a la implementación de programas sanitarios de acceso universal) y de las peculiaridades clínicas que pueden presentar en población de origen afro americano. Más importante aún, el impacto que dichos casos tienen no sólo en indicadores sanitarios y económicos sino también en la necesidad de retomar programas abandonados o considerados no relevantes para la población chilena. Entre ellas, la prevalencia de infecciones de trasmisión sexual (ej. Sífilis, VIH y SIDA) y su concurrencia con embarazo, el aumento de patología cervical invasora, casos de cólera, parasitosis enterales, escabiosis y pediculosis (condiciones más 
prevalentes donde hay hacinamiento habitacional, condiciones inadecuadas de preservación de alimentos o su comercialización informal).

Como Sociedad Chilena de Obstetricia y Ginecología, el tema nos preocupa e importa, es por ello que hemos comenzado a considerar la inclusión en la temática de discusión, tanto de reuniones clínicas como de cursos y congresos, temas relacionados con migrantes y qué debe saber y hacer el especialista en dicho escenario. En relación al cuidado prenatal, enfatizar la importancia de la aplicación oportuna de herramientas tales como certificación ecográfica temprana de la edad gestacional, promover la importancia del control prenatal y el autocuidado durante el embarazo (respetando cultura y superando barreras idiomáticas), educar sobre los derechos de la mujer embarazada que trabaja, garantizar el tamizaje para VIH y Sífilis tanto antes, durante y después el embarazo, prescribir suplementos nutricionales y vacunas, facilitar el acceso a la toma de papanicolau, educar sobre beneficios y asesorías sociales y otorgar información y acceso oportuno al diagnóstico y tratamiento de patologías incluidas en la canasta GES, entre otras. Junto a ello, como sociedad queremos estimular el registro de casos y patologías a fin de coordinar esfuerzos y adaptar políticas a escenarios regionales particulares.

Una tarea como ésta no implica más esfuerzo ni más trabajo sino simplemente el estimular el espíritu solidario y profesional que todos profesamos $y$ buscamos enseñar a nuestros educandos.

\section{Dr. Mauricio Cuello Fredes \\ Profesor Titular Obstetricia y Ginecología \\ Editor en Jefe \\ Revista SOCHOG}

